Article

\title{
Ground Tire Rubber Recycling in Applications as Insulators in Polymeric Compounds, According to Spanish UNE Standards
}

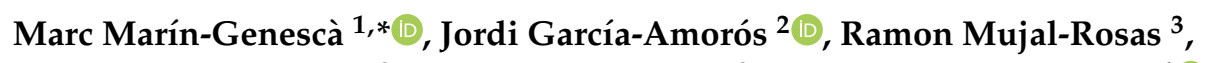 \\ Lluís Massagués Vidal ${ }^{2}$, Jordi Bordes Arroyo ${ }^{2}$ and Xavier Colom Fajula ${ }^{4}$ \\ 1 Mechanical Engineering Department, Escola Tècnica Superior d'Enginyeria Química-Universitat Rovira i \\ Virgili (ETSEQ-URV), 43007 Tarragona, Spain \\ 2 Electrical Engineering Department, Escola Tècnica Superior d'Enginyeria-Universitat Rovira i \\ Virgili (ETSE-URV), 43007 Tarragona, Spain; jordi.garcia-amoros@urv.cat (J.G.-A.); \\ lluis.massagues@urv.cat (L.M.V.); jordiba76@gmail.com (J.B.A.) \\ 3 Electrical Engineering Department, Escola d'Enginyeria de Terrassa-Universitat Politècnica de \\ Catalunya (EET-UPC), 08222 Terrassa, Spain; mujal@ee.upc.edu \\ 4 Chemical Engineering Department, Escola d'Enginyeria de Terrassa-Universitat Politènica de \\ Catalunya (EET-UPC), 08222 Terrassa, Spain; xavier.colom@upc.edu \\ * Correspondence: marc.marin@urv.cat; Tel.: +34-618-787-469
}

Received: 1 June 2020; Accepted: 31 July 2020; Published: 2 August 2020

check for updates

\begin{abstract}
In the present research, we investigated the conceivable outcomes of using ground tire rubber (GTR) particle polymeric blends. Special methods of restoring tires that are no longer in use include GTR retreading, GTR blending destined for recycling to attain raw substances utilized in other industrial application production processes, and the valorization of GTR for power/energy generation. The recycling of end-of-life tires enables the recovery of rubber, steel, and fibers, all of which are valid on the market as raw materials to be used for other processes. There are methods to recycle GTRs in a clean and environmentally friendly way. In the present research, several industrial applications of GTR polymer blends were developed and compared with standard values from the Spanish Association for Standardization (UNE) and the International Electrotechnical Commission (IEC). In order to analyze the viability in many of the industrial applications selected, certain compounds obtained from the GTR polymer blends were analyzed regarding their use in nine low requirement insulator applications. The research and analysis developed in this manuscript used standard values from the UNE and IEC, and these standard values were compared with the test values. The obtained results were used to provide an application list that could be helpful for industrial applications. In this research, the pre-owned polymers were as follows: polypropylene (PP), high-density polyethylene (HDPE), polystyrene (PS), acrylonitrile butadiene-styrene (ABS), ethylene vinyl acetate (EVA), polyvinyl chloride (PVC), and polyamide (PA). The filler used was GTR with particle sizes lower than 200 microns. The amounts of GTR particles in the compound materials were $0 \%$ (raw polymer), 5\%, 10\%, 20\%, 40\%,50\%, and 70\% (the latter being found in polymeric blends). We discovered six plausible modern applications of GTR polymer blends as indicated by the UNE and IEC standards.
\end{abstract}

Keywords: GTR recycling; rubber waste; electrical properties; mechanical properties; insulators; polymer composites; tire recycling 


\section{Introduction}

Rubber waste is an extreme problem, mainly because rubber biodegradation requires a long duration and has dangerous environmental effects. Tires contain nearly 50\% rubber, and the global production of rubber substances over the last several years was almost $30 \mathrm{Mt}$ [1]. Tire industries are the principle users of rubbers (65\% of worldwide manufacturing) and generate huge amounts of rubber waste. Therefore, rubber recycling is frequently defined as tire recycling due to the composition of tires (nearly $50 \%$ rubber). Currently, 1.5 billion tires each year are discarded, containing up to $90 \%$ vulcanized rubber that cannot be recycled or reprocessed without problems due to the crosslinked structure [2,3]. Currently, controlling where used tires end up has become a large challenge; therefore, rubber recycling is one of the issues being researched. Vulcanized rubbers are used in tire manufacturing processes because thermoset materials can sustain excessive mechanical and thermal conditions while their properties do not change with temperature. Table 1 shows the characteristic tire compositions for vehicles [4-7].

Table 1. Typical compositions of car tires.

\begin{tabular}{cc}
\hline Material Type & Car Tire (wt.\%) \\
\hline Rubber & $42-48$ \\
Carbon black & $24-28$ \\
Metal & $12-16$ \\
Textile & $4-6$ \\
Additives & $9-12$ \\
\hline
\end{tabular}

Discarded tires have numerous properties and can, therefore, result in useful materials. The accumulation of tires causes fire hazards [8], and their combustion emits poisonous products that pollute the environment, which is unsafe for humans and animals. In addition, carbon dioxide released during a fire influences the greenhouse effect [9]. The most efficient approach to avoid these issues would be changing used ground tire rubber into new materials with interesting properties. Research has been done on reusing end-of-life tires for energy recovery $[10,11]$ and pyrolysis [12]. For instance, waste tires are used as a fuel source in concrete furnaces, which is more natural compared to coal ignition. However, many drawbacks have been reported as a burning tire releases hazardous gases and only recovers $25 \%$ of the energy used for rubber production [13].

Vulcanized waste rubbers are difficult to recycle and the crosslink structure of rubber makes any recycling technique very difficult [14]. Therefore, an interesting option is to blend waste tires with polymers to decrease the final cost of the products due to a lower amount of virgin compounds being used. Waste tires must be shredded (ground) into smaller particles (micrometer size) for an easier dispersion in thermoplastic matrices. Shredded tires can be used in raw polymers along with rubbers, thermoplastics, and thermoset blends for civil engineering, automotive components, sports equipment, and many other applications [15-17]. The manufacturing of ground tire rubber (GTR) polymer blends consumes a large amount of waste tires [18,19].

Thermoplastic blending with GTR may be a promising field of study due to the use of an excellent balanced compound that replaces the raw polymer with GTR [20]. Different research groups have found that blends of GTR and thermoplastic polymers are materials with very interesting features, such as a low cost, high sustainability, and easy preparation considering that no prior treatment is required [21-23]. Regardless of the type of polymeric thermoplastic used, GTR blends lack compatibility, mainly when the amount of GTR is higher than $20 \%$. Therefore, it is often necessary to improve this lack of compatibility by performing surface treatments on GTR [24-26]. Considering this, we compared the results for insulators with low requirements in two programs, the Spanish Association for Standardization (UNE) and the International Electrotechnical Commission (IEC). We obtained test results of the dielectric and mechanical characterizations from research labs. 
The UNE is a standardization organization in Spain, designated by the Ministry of Economy, Industry and Competitiveness and is dependent on the European Commission. The UNE's standards are used for validating material applications [27]. The IEC is the world's leading organization for the preparation and publication of international standards for all electrical and electronic technologies. These two standards (the UNE and IEC) will be used to compare the values of specific industrial electrical applications with the dielectric and mechanical values obtained from experimental procedures for compounds of different thermoplastic GTR blends with particle sizes of less than $200 \mu \mathrm{m}$. The IEC and UNE require certain properties for each analyzed application. For instance, in the mechanical field, the elongation at break and tensile strength are properties required for many applications. Similarly, the electrical criterion defines the conductivity, loss tangent, and resistivity of properties that are required.

\section{Materials and Instruments}

\subsection{Materials}

The polymers used in this study were: polyvinyl chloride (PVC); high-density polyethylene (HDPE); ethylene vinyl acetate (EVA) copolymer (18\% of vinyl acetate and $82 \%$ ethylene); polypropylene (PP); acrylonitrile butadiene-styrene (ABS), which is composed of $30 \%$ acrylonitrile, $20 \%$ butadiene, and $50 \%$ styrene; polyamide 6 (PA 6), also known as nylon 6; polystyrene (PS). The properties of these seven polymeric materials are summarized in Table 2 . We analyzed the ground tire rubber (GTR) with a microparticle size under $200 \mu \mathrm{m}$ using thermal gravimetric analysis (TGA) itest with the carbon black compound at approximately $35 \%$. The GTR was ground by sieving into one particle size, lower than 200 microns.

Table 2. The physical properties and processing temperatures of the mixing machine. The pressing temperatures were at a constant pressure of 200 bar for each material. Polyvinyl chloride (PVC); high-density polyethylene (HDPE); ethylene vinyl acetate (EVA); polypropylene (PP); acrylonitrile butadiene-styrene (ABS); polyamide 6 (PA 6); polystyrene (PS).

\begin{tabular}{cccccc}
\hline $\begin{array}{c}\text { Polymer } \\
\text { Type }\end{array}$ & Commercial Name & $\begin{array}{c}\text { Fluidity Index or Melt } \\
\text { Flow Index }(\mathbf{g} / \mathbf{m i n})\end{array}$ & $\begin{array}{c}\text { Density } \\
\left(\mathbf{k g} / \mathbf{m}^{3}\right)\end{array}$ & $\begin{array}{c}\text { Processing } \\
\text { Temperature }\left({ }^{\circ} \mathbf{C}\right)\end{array}$ & $\begin{array}{c}\text { Pressing } \\
\text { Temperature }\left({ }^{\circ} \mathbf{C}\right)\end{array}$ \\
\hline PVC & Etinox & 1.35 & 1.225 & $195-200$ & 210 \\
EVA & Alcudia PA 539 type & 0.20 & 937 & $105-110$ & 120 \\
HDPE & Alcudia 4810-B & 1.35 & 960 & $150-155$ & 170 \\
PA 6 & Ultramid B3S & 1.55 & 1130 & $195-200$ & 210 \\
ABS & Terluran ${ }^{\circledR}$ HH-106 & 1.45 & 1050 & $180-185$ & 195 \\
PP & Isplen ${ }^{\circledR}$ 099 K2M type & 0.55 & 902 & $155-165$ & 165 \\
PS & Polystyrol 486 M & 1.45 & 1050 & $180-185$ & 195 \\
\hline
\end{tabular}

\subsection{Preparation of the Compounds}

The reused tire powder was dried in an oven at $100{ }^{\circ} \mathrm{C}$ for one day $(24 \mathrm{~h})$. We prepared five specimens of each selected polymer/GTR compound, which had different amounts of GTR: $0 \%, 5 \%$, $10 \%, 20 \%, 40 \%, 50 \%$, and $70 \%$. The blending procedure was finished with a Brabender mixing machine, at various temperatures, to forestall the debasement of the polymer, and the blending time was restricted to $4 \mathrm{~min}$. The polymer/GTR blends were obtained by utilizing a hot plate press at $100 \mathrm{kN}$ at various temperatures for $10 \mathrm{~min}$ to form the polymeric compounds. The cooling stage was finished with a shut water circuit, which was held in a similar press and weight for $5 \mathrm{~min}$. The tests were appropriately set up as indicated by the determinations of the ASTM-D-638-V standard. One specimen of the raw polymer was likewise arranged with similar necessities to acquire practically identical outcomes, to do a comparison study between the polymer without GTR and with GTR loads. Five specimens were used for testing. 


\subsection{Mechanical Analysis Performed}

Tensile tests were conducted using a universal machine Instron 3366 following the specifications of the ASTM-D-412-98. The speed of the test was set at $20 \mathrm{~mm} / \mathrm{min}$. The testing temperature was $23 \pm 2{ }^{\circ} \mathrm{C}$ with the relative humidity at $50 \% \pm 5 \%$. The studied properties include the tensile strength and the percentage of the elongation at break versus the tire rubber contents. The qualitative toughness of the samples was calculated from measurements of the area of the strength-strain curves to compare the results. We conducted a statistical analysis on the mechanical testing data to determine the significance of the values. Five specimens were analyzed, and the average and standard deviation were calculated. This paper reports lab tests directed on a progression of seven polymer grids blended with different amounts of GTR $(0 \%, 5 \%, 10 \%, 20 \%, 40 \%, 50 \%$, and $70 \%)$ to assess the specific mechanical parameters of the compounds and examine its application in the industrial field with the stress-strain test application. The mean and standard deviation (maximum $4 \%$ ) were determined for each parameter, and samples that did not meet the specifications were removed.

\subsection{Dynamic Electric Analysis}

Dielectric analysis was performed to measure the parameters by means of dynamic electric analysis (DEA) with a BDS40 wide band dielectric spectrometer, which joined a Novocontrol Novotherm temperature sensor and used pressure molds with a $2 \mathrm{~cm}$ width. The information was obtained by utilizing an equal plate sensor. For this test, the samples were pushed between the anode and cathode in contact with the specimen. The conductivity was estimated using DEA. The parameters must be set before beginning the dielectric test. The samples of the GTR polymeric compounds were characterized with the ASTM D-150 standard; the specimens were barrel shaped, $2.5 \mathrm{~mm}$ in diameter, and $0.1 \mathrm{~mm}$ in thickness. After obtaining the results, the dielectric potential of the mixture of materials was analyzed in depth.

\section{Results and Discussion}

\subsection{Mechanical Test Results}

When examining the chart of the elongation at break (Figure 1a), it can be seen that the materials that have uncommon elongation at break attributes are featured. These are, noticeably, the EVA copolymer $(>700 \%)$ and, as a runner up, the PP polymer (346.7\%). With the increased addition of GTR particles, the lengthening properties of PP significantly fell. The polymer with better lengthening properties was the EVA with rates of GTR up to 10-20\%. Enough elongation behavior was observed for the EVA compounds: EVA + 10\% GTR: $438 \%$; EVA + 20\% GTR: $351.53 \%$. For the PP with a similar GTR amount (10-20\%), the stretching conduct was poor, arriving at $15 \%$ of the neat polymer without GTR (PP + 10\% GTR: 41.73\%; PP + 20\% GTR: 33.89\%).

For the remainder of the materials, the PS and the HDPE demonstrated certain extension properties, although they did not arrive at estimations of 100\% of elongation at break (PS: $66.27 \%$ and HDPE: $50.12 \%)$. The addition of GTR negatively affected these properties but suffered a drop in percent elongation with 20\% GTR (PA +20\% GTR: 23.30\%; HDPE +20\% GTR: 20.01\%), which already represents probabilities much less than $50 \%$ of the polymer blends. Analyzing the elongation at break of the GTR compounds [28-30], the optimum behavior was for EVA compounds, which for $0 \%, 5 \%, 10 \%$, and $20 \%$, had values of $704 \%$ to $528 \%, 437 \%$, and $351 \%$, because of the decreases from nearly $30 \%$ to $50 \%$ for the amounts of GTR.

From high amounts of GTR, the obtained values were lower than for the neat polymer, indicating that this decrease can be of great impact. The reduction of the deformation capability of the elastomer impacts the lower limit in the elongation at break and is related to the imperfect interfacial adhesion between components. The relaxation of the polymers had very low values for the elongation at fracture properties. The prevalence of poor adhesion between levels is a particularly critical result [31,32]. The mechanical properties of the blend are poor due to the lack of adhesion between the two phases. 
This is related to the large particle size of the GTR particles, their surface characteristics, and their crosslinked structure, which hinder its molecular entanglement with the polymer. To overcome these problems, several attempts have been made to compatibilize both components in order to obtain thermoplastics compounds with better properties [14].

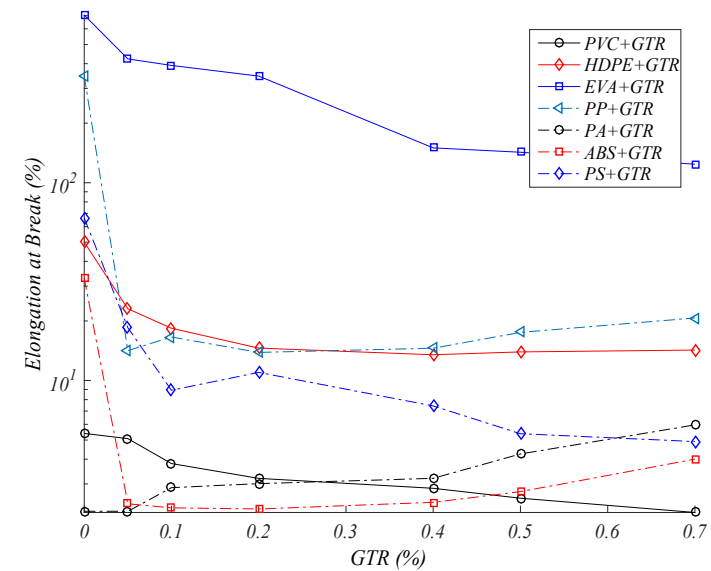

(a)

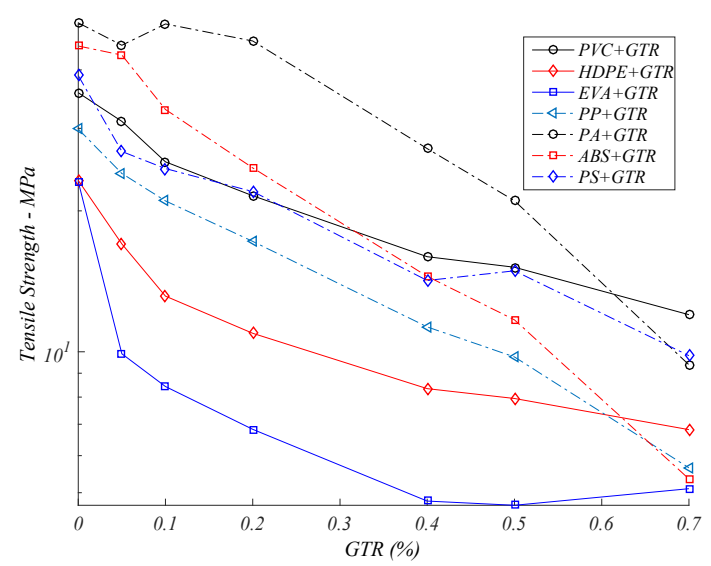

(b)

Figure 1. (a) Elongation at break (\%), (b) tensile strength (MPa), for seven polymers/ground tire rubber (GTR) concentrations with a particle size $<200 \mu \mathrm{m}$.

In the comparative graph of tensile strength (Figure $1 \mathrm{~b}$ ), we deduced that the materials analyzed had comparable characteristics of tensile strength. Of all of them, those with a greater strength to breakage were, in order, PA, ABS, PS, and PVC. In a completely distinct way, the PA polymer reached nearly $50 \mathrm{MPa}$, and in second position was the ABS polymer (45 MPa) from the addition of GTR particles. In general, small amounts of GTR additive (5-20\%) resulted in a worse conduct of the tensile strength. Comparatively, the polymer with the exceptional breaking electricity properties was the PA and, with chances of GTR of up to $20 \%$, a good feature of tensile strength ( $47.39 \mathrm{MPa}$ ) was observed; however, for possibilities of GTR greater than $20 \%(40 \%, 50 \%$, and $70 \%)$, the tensile strength dropped to values of nearly $50 \%$ of the tensile strength of the pure polymer, without the GTR additive.

Other polymeric materials, in general, demonstrated good tensile strength behaviors, although for PS and EVA (38.89 MPa and 23.1 MPa, respectively), the addition of GTR negatively influenced this feature, and they suffered a drop in breaking strength with GTR contents higher than $20 \%(40 \%$, $50 \%$, and $70 \%$ ). For example, for the PS $+40 \% / 50 \% / 70 \%$ GTR, the subsequent values of tensile strength were: $19.1,15.9$, and $11.8 \mathrm{MPa}$, respectively, and for EVA compounds $+40 \% / 50 \% / 70 \%$ GTR, the values of tensile strength were: 7, 5.7, and $5.5 \mathrm{MPa}$, respectively, from which they already represent less than $50 \%$ of tensile strength ( $\mathrm{MPa}$ ) of the polymeric matrix (the polymer without GTR), if we consider the neat EVA: $23 \mathrm{MPa}$ and $12.7 \mathrm{MPa}$ for EVA + 10\% GTR. These analyzed properties are interesting by the UNE and IEC standards. In general, the trend is to decrease the tensile strength with the presence of GTR, with only one exception-PA for low GTR amounts (5-20\%).

\subsection{Electrical Results}

We performed analysis of the electrical properties: the conductivity, loss factor ( $\operatorname{Tg} \delta)$, and electric resistivity analysis for compounds with GTR contents (at $30^{\circ} \mathrm{C}$ ), and at $50 \mathrm{~Hz}$ frequency were analyzed for the GTR compounds. The highlighted results demonstrate that the PA samples had the maximum conductivity of the samples analyzed (see Figure 2a). With the increase in GTR, the conductivity of the samples, in most of the analyzed cases, was elevated up to two orders of the value for natural PA. From $0 \%$ to $5 \%$, the conductive behavior was more heterogeneous, with the PS and PP being the least conductive. For pure PS and PP, at $50 \mathrm{~Hz}$, they had conductivities of $10^{-13}$ and $10^{-11} \mathrm{~S} / \mathrm{cm}$, respectively. For 70\% GTR contents, the PS was revealed as the maximum insulating material $\left(10^{-14} \mathrm{~S} / \mathrm{cm}\right)$; likewise, 
$\mathrm{ABS}+70 \%$, which, at a commercial frequency $(50 \mathrm{~Hz})$, observed a conductivity of $10^{-10} \mathrm{~S} / \mathrm{cm}$. For the natural PVC ( $0 \%$ GTR), the bottom conductivity without GTR were HDPE, PS, and PP, followed by EVA, PVC, and ABS, and eventually the PA was observed as the least resistive.

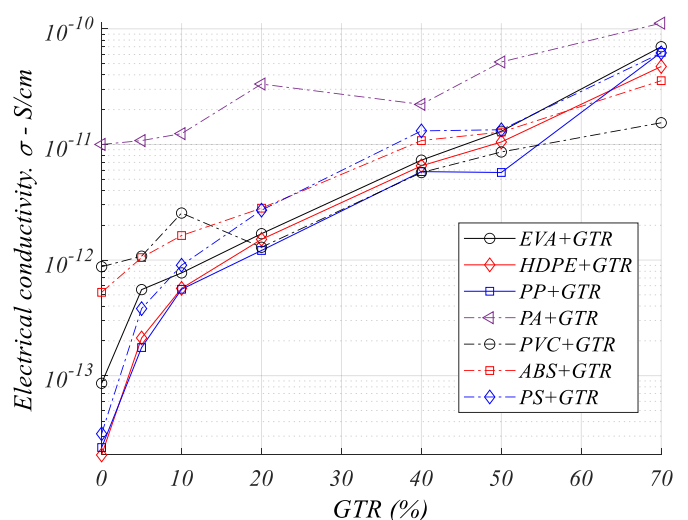

(a)

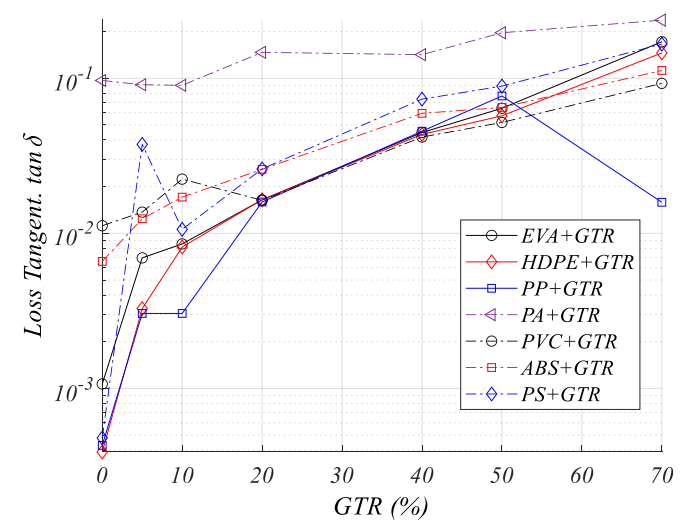

(b)

Figure 2. (a) Electrical conductivity $(\mathrm{S} / \mathrm{cm})$, and the (b) loss tangent (Tan $\delta)$ for different polymers/GTR concentrations with a particle size of $<200 \mu \mathrm{m}$. The frequency was fixed at $50 \mathrm{~Hz}$ and $30^{\circ} \mathrm{C}$.

Thus, with the addition of the GTR, the conductive behavior of virtually all polymers tended to converge. The PA (polar polymer), which remained two orders of magnitude above the rest of the polymers analyzed, was, for the $40-50 \% \mathrm{GTR}, 4.9 \times 10^{-13}$ and $1.7 \times 10^{-12} \mathrm{~S} / \mathrm{cm}$, and $10^{-15} \mathrm{~S} / \mathrm{cm}$ for the rest of the polymers, and ABS and PS, for the $40 \%$ of GTR, reached conductivities of $1.1 \times 10^{-14}$ and $1.3 \times 10^{-14} \mathrm{~S} / \mathrm{cm}$, respectively. The general trend for the GTR composites was the resistivity drop and conductivity rise of the components. For the EVA + GTR and PA + GTR behaviors, the conductivity drops were less than for the other polymers, as the GTR presence negatively affected the conductivity behavior. In general, these results can be interpreted as a worse electrical behavior (less electrical resistivity) in GTR composites due to the carbon black (CB) presence in the GTR composites [33-35].

Watching the tangent $(\mathrm{Tg})$ of $\delta$ dissected in the instance of the seven polymers + GTR (see Figure 2b), the material with the most noteworthy digression in the tangent of delta was polyamide, which, without GTR addition, presented estimations of $10^{-1}$ and so we concluded that GTR influenced the $\mathrm{Tg}$ of $\delta$ behavior in the GTR polymeric blends analyzed as it expands the Tangent of $\delta$ to a significant degree. In this way, the materials with a lower Tg of $\delta$ were PP, HDPE, EVA, and PS (0.001); these are trailed by PVC and ABS (0.01). Lastly, with a more noteworthy Tg of delta, was PA (0.1). For increments of the extent of the GTR particles loads, this proportion changed, tending to combine all the polymers in the tangent of delta $10^{-1}$, apart from PP. The polyamide encounters expanded the $\mathrm{Tg} \delta$ with GTR rates of $40-70 \%$ and the $\mathrm{Tg}$ of delta went from 0.1 to 10 .

By and large, for low contents of GTR (5-20\%), the Tg of $\delta$ was heterogeneous and as the GTR increased, the conduct began to be assimilated. As a rule, the Tg of $\delta$ sways somewhere in the range of $10^{-1}$ and $10^{-2}$ for practically all polymers except for the PA; therefore, the expansion of GTR amounts, in polymer blends, increased the $\mathrm{Tg} \delta$ values. PVC had a variable conduct to a significant degree from the expansion of GTR. In general, we showed (Figure 2b) that GTR presence affected this property in all the polymers, but significantly less so for the EVA- and PA-GTR compounds analyzed, in which a more stable $\operatorname{Tg} \delta$ behavior was seen.

The electrical resistivity $(\Omega \cdot \mathrm{cm})$ results, in Figure 3 , show that PP and EVA were the most resistivity polymers, followed by HDPE. Regarding the GTR polymeric blend (polymer + GTR) resistivity, we can observe how the resistivity values decreased with the incorporation of GTR for PP + GTR and EVA + GTR. At $5-10 \%$ of GTR, the electrical resistivity behaviors, in most of polymeric compounds, were quite similar. Despite the decrease in electrical resistivity, the values are enough for electrical insulation in the different analyzed thermoplastic compounds with GTR. 


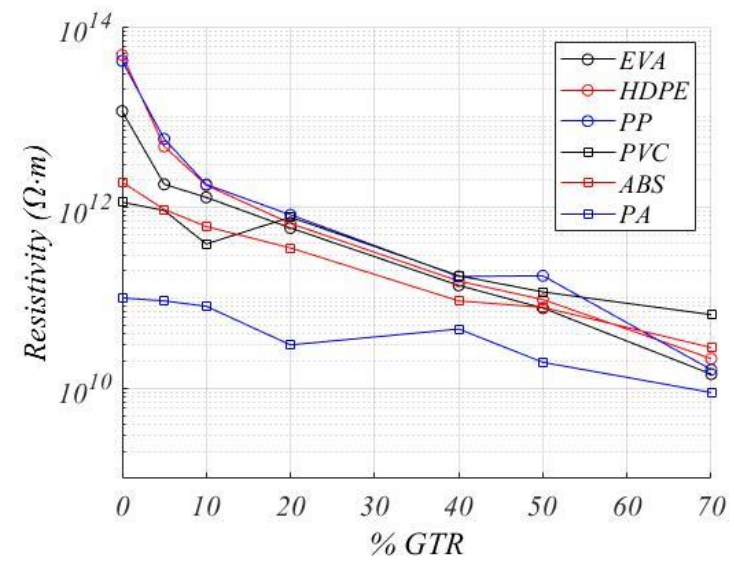

Figure 3. The electrical resistivity $(\Omega \cdot \mathrm{cm})$, for different polymers/GTR contents with a particle size $<200 \mu \mathrm{m}$. The frequency was fixed at $50 \mathrm{~Hz}$ and $30{ }^{\circ} \mathrm{C}$.

\subsection{Results and Discussion of GTR Influence}

From the analysis of the dielectric results, three main conclusions are drawn: The conductivity and the phase angle increased with the percentage of GTR. The presence of GTR (and more specifically, carbon black, as the main component of GTR) created dielectric changes in compounds. Thus, it follows that the structure changes created by the presence of GTR in the polymer can also create changes (increases) in the conductivity behavior due to the presence of carbon atoms (conductive) in the compounds. The study of the dielectric properties of GTR-reinforced polymers demonstrated that, at the same temperature and frequency, the presence of ground tire rubber in thermoplastics increased their conductivity and tangent of delta values and, consequently, decreased their electrical resistivity. In each case, evolution was created by changes in the polarization (particularly by orientation polarization), through changes in the measured properties [35-38]. The presence of ground tire rubber caused the changes in dielectric behavior by changing the structure and the conductivity of the polymer, in particular due to the carbon black contained in GTR, because carbon black is the electrically conductive element in GTR. The polymers that presented more stability in the electrical properties analyzed were PA and EVA.

The electrical properties of an insulator must be adopted for special uses, in which case $50 \mathrm{~Hz}$ is the frequency of interest as this is the frequency insulators use. We found that the dielectric and mechanical characteristics of the thermoplastics decreased significantly from $10 \%$ to $20 \%$ of GTR in the polymer tested. Insulating materials are generally used to isolate the elements of the electrical grid and insulate them in relation to the other elements [39,40], and, in relation to the earth, materials are desired to have the smallest conductivity possible with acceptable mechanical properties.

In this sense, as seen in Table 3, when adding GTR in the polymeric matrix (5-10\%) for PVC, and PA composites, the elongation at break (\%) of the compound increased, although other tensile strength properties decreased at the same time, and for the other cases, the elongation at break (\%) became worse. However, for GTR contents above $20 \%$, all mechanical properties decreased, except for the PA composites. In Table 3 (mechanical properties) and Table 4 (electrical properties), the compounds that improved with the addition of GTR are shown in bold. In this case, improve means: an increase in the mechanical values and a decrease in the values of conductivity and loss tangent $(\operatorname{Tg}$ of $\delta$ ), because these are the desired properties of an electrical insulator.

As we can see in Tables 3 and 4, few compounds improved the values from the net thermoplastic polymer without GTR. As can be seen in Table 3, the most elevated estimations of property are related to the neat polymer $(0 \%$ GTR), with certain exemptions as featured in the table. For HDPE, PA, and PVC, some mechanical properties were improved by the expansion of microparticles $(<200 \mu \mathrm{m})$ of GTR in polymeric blends. The mechanical parameters were overall impacted by the GTR presence. Essentially, at the mechanical level, the properties of the GTR polymer blends were maintained, somewhere in the 
range of $10 \%$ and $20 \%$ of the GTR particle loads (for particles size $\leq 200$ microns). The interaction of the polymers with the GTR particles was somewhat low, and consequently, for values higher than $20 \%$ GTR in the polymeric framework, the mechanical properties decreased significantly.

Table 3. Analysis of the highest mechanical property values of each property, and the composites regarded (size particle of GTR $<200 \mu \mathrm{m}$ ).

\begin{tabular}{ccc}
\hline Polymer Composite & Tensile Strength (MPa) & Elongation at Break (\%) \\
\hline PVC/GTR & $35.75(0 \%$ GTR) & $\mathbf{6 . 3 1}(\mathbf{5} \%$ GTR) \\
EVA/GTR & $23.08(0 \%$ GTR) & $704.6(0 \%$ GTR $)$ \\
HDPE/GTR & $\mathbf{2 5 . 5 1}(\mathbf{5 \%}$ GTR) & $50(0 \%$ GTR) \\
PP/GTR & $29.9(0 \%$ GTR $)$ & $346.71(0 \%$ GTR $)$ \\
ABS/GTR & $44.98(0 \%$ GTR) & $32.91(0 \%$ GTR $)$ \\
PA/GTR & $50.41(0 \%$ GTR) & $\mathbf{8 . 4 6}(\mathbf{7 0} \%$ GTR) \\
PS/GTR & $38.89(0 \%$ GTR) & $66.27(0 \%$ GTR $)$ \\
\hline
\end{tabular}

Table 4. Analysis of the suitable electrical property values of each property, and the composite regarded (size particle of GTR $<200 \mu \mathrm{m}$ ).

\begin{tabular}{cccc}
\hline Polymer Composite & Conductivity $\boldsymbol{\sigma}(\mathrm{S} / \mathrm{cm})$ & Resistivity $(\boldsymbol{\Omega} \cdot \mathbf{c m})$ & Loss Tangent \\
\hline PVC/GTR & $8.76 \times 10^{-13}(0 \%$ GTR $)$ & $1.14 \times 10^{12}(0 \%$ GTR $)$ & $0.01119775(0 \%$ GTR $)$ \\
EVA/GTR & $8.59 \times 10^{-14}(0 \%$ GTR $)$ & $1.16 \times 10^{13}(0 \%$ GTR $)$ & $0.001068(0 \%$ GTR $)$ \\
HDPE/GTR & $2.06 \times 10^{-14}(0 \%$ GTR $)$ & $4.85 \times 10^{13}(0 \%$ GTR $)$ & $0.00038912(0 \%$ GTR $)$ \\
PP/GTR & $2.39 \times 10^{-14}(0 \%$ GTR $)$ & $4.18 \times 10^{13}(0 \%$ GTR $)$ & $0.00042918(0 \%$ GTR $)$ \\
ABS/GTR & $5.26 \times 10^{-13}(0 \%$ GTR $)$ & $1.9 \times 10^{12}(0 \%$ GTR $)$ & $0.00659429(0 \%$ GTR $)$ \\
PA/GTR & $1 \times 10^{-11}(0 \%$ GTR $)$ & $9.96 \times 10^{10}(0 \%$ GTR $)$ & $\mathbf{0 . 0 9 0 1 0 3 7 2 ~ ( 1 0 \% ~ G T R ) ~}$ \\
PS/GTR & $3.14 \times 10^{-14}(0 \%$ GTR $)$ & $3.18 \times 10^{13}(0 \%$ GTR $)$ & $0.00047897(0 \%$ GTR $)$ \\
\hline
\end{tabular}

In Table 5, the results for the different polymeric compounds with $10 \%$ of GTR loads are shown. We can see how the results for low contents of GTR give reasonable enough results for low requirement insulator applications, as is described in the next section (Section 4).

Table 5. Mechanical and electrical test results with 10\% GTR.

\begin{tabular}{cccccc}
\hline Composite & $\begin{array}{c}\text { Tensile } \\
\text { Strength } \mathbf{( M P a})\end{array}$ & $\begin{array}{c}\text { Elongation at } \\
\text { Break } \mathbf{( \% )}\end{array}$ & $\begin{array}{c}\text { Conductivity } \\
\boldsymbol{\sigma}(\mathbf{S} / \mathbf{c m})\end{array}$ & $\begin{array}{c}\text { Loss } \\
\text { Tangent }\end{array}$ & $\begin{array}{c}\text { Resistivity } \\
\boldsymbol{\rho}(\boldsymbol{\Omega} \cdot \mathbf{c m})\end{array}$ \\
\hline EVA+10\% GTR & 12.7 & 438 & $1.29 \times 10^{12}$ & 0.00854714 & $1.29 \times 10^{12}$ \\
\hline PVC+10\% GTR & 32 & 5.4 & $3.93 \times 10^{11}$ & 0.022369 & $3.93 \times 10^{11}$ \\
\hline HDPE+10\% GTR & 23.8 & 27 & $1.76 \times 10^{12}$ & 0.00815887 & $1.76 \times 10^{12}$ \\
\hline PP+10\% GTR & 22.4 & 41.7 & $1.79 \times 10^{12}$ & 0.0030445 & $1.79 \times 10^{12}$ \\
\hline PA+10\% GTR & 42.0 & 1.7 & $8.05 \times 10^{10}$ & 0.09010372 & $8.05 \times 10^{10}$ \\
\hline ABS+10\% GTR & 33.4 & 4.8 & $6.13 \times 10^{11}$ & 0.01712194 & $6.13 \times 10^{11}$ \\
\hline PS+10\% GTR & 28.5 & 37.5 & $1.11 \times 10^{12}$ & 0.0106162 & $1.11 \times 10^{12}$ \\
\hline
\end{tabular}

\section{Development of Industrial Applications}

After obtaining the results of the different samples, and analyzing the dielectric and mechanical properties, in this part, the real values are compared with values of the appropriate standards to determine the feasibility of the compounds. The final application will be defined from the study of the UNE and IEC regulations (See Table 6) [41,42]. Different applications have been studied for the blends that were tested previously, and, for the most suitable materials, some electrical applications have been developed that may be interesting. This study focused on applications with low electrical 
requirements. Thus, the following possible applications have been selected: Table 6 shows applications with low requirements insulators.

Table 6. Selected applications to compare values from the UNE/IEC standards versus measured data.

\begin{tabular}{|c|c|c|}
\hline Application Type & Specific Industrial Application & Number of Applications \\
\hline $\begin{array}{l}\text { Medium high voltage } \\
\text { application }\end{array}$ & $\begin{array}{l}\text { Fillers for electrical cables } \\
\text { Insulators for overhead power lines }\end{array}$ & 2 \\
\hline $\begin{array}{l}\text { Electrical applications } \\
\text { for low voltage }\end{array}$ & $\begin{array}{l}\text { Splice for cables and spacers for power lines } \\
\text { Trays for electrical cables. Cable pipes } \\
\text { Electric canalizations } \\
\text { Electrical insulating tape } \\
\text { Low voltage electrical insulation applications for } \\
\text { electric fences and shepherds }\end{array}$ & 5 \\
\hline $\begin{array}{l}\text { Labor safety and } \\
\text { occupational } \\
\text { risk prevention }\end{array}$ & $\begin{array}{c}\text { Protection on hands and arms (dielectric gloves) } \\
\text { Footwear for work use (insulating and highly } \\
\text { resistive) }\end{array}$ & 2 \\
\hline & Total applications & 9 \\
\hline
\end{tabular}

The possible applications selected have low requirements in common, but minimum mechanical, electrical, and other requirements are needed. Therefore, the suitability of the materials selected for the applications considered from the current regulations and the standards for each case are justified below in Table 7.

Table 7. Application standards code related: the Spanish Association for Standardization (UNE) and the International Electrotechnical Commission (IEC).

\begin{tabular}{|c|c|}
\hline Consultation Standard Code & Rule Specific Content \\
\hline $\begin{array}{l}\text { UNE-EN 60335-2-76, IEC 60335-2-76, UNE-EN } \\
60.831 \text {-1, ITC-BT-39, 22, 23, } 24\end{array}$ & $\begin{array}{l}\text { Components of electrical circuits. } \\
\text { Insulation for electric shepherds. }\end{array}$ \\
\hline IEC 61854 & $\begin{array}{l}\text { Auxiliary elements for power lines. } \\
\text { Spacer for power lines }\end{array}$ \\
\hline $\begin{array}{l}\text { IEC } 60840 \\
\text { UNE HD } 628\end{array}$ & $\begin{array}{l}\text { Connecting elements for electrical cables. } \\
\text { Splice for electrical cables }\end{array}$ \\
\hline $\begin{array}{l}\text { UNE EN 61537, UNE EN 50085-1: IEC } 61537 \\
\text { (EN 61537) }\end{array}$ & $\begin{array}{l}\text { Auxiliary elements for power lines. } \\
\text { Pipes for electrical cables }\end{array}$ \\
\hline $\begin{array}{l}\text { UNE-EN ISO 20345/6/7: } 2005 \\
\text { UNE } 53510\end{array}$ & $\begin{array}{l}\text { Regulations on footwear for work use (insulating), } \\
\text { anti-electrostatic, insulating and high electrical resistance. } \\
\text { Physical criteria on protective equipment }\end{array}$ \\
\hline UNE-21115, IEC 502 & Criteria on insulation for overhead power lines \\
\hline IEC 60454-3 & Insulating elements for electrical connections \\
\hline UNE-EN 1149-5: 2008. & Personal protective equipment and anti-electrostatic clothing \\
\hline UNE-EN 60903: 2005 & Individual Protection Equipment. Dielectric gloves \\
\hline UNE-HD 620-1 & $\begin{array}{c}\text { Electrical distribution cables with extruded insulation, rated } \\
\text { voltage from 3.6/6 (7.2) } \mathrm{kV} \text { to } 20.8 / 36(42) \mathrm{kV} \text {. } \\
\text { Part 1: General Requirements }\end{array}$ \\
\hline UNE-HD 632-1 & $\begin{array}{l}\text { Extruded insulated power cables and their accessories for rated } \\
\text { voltages greater than } 36 \mathrm{kV}(\mathrm{Um}=42 \mathrm{kV}) \text { up to } 150 \mathrm{kV}(\mathrm{Um}= \\
170 \mathrm{kV}) \text {. Part } 1 \text { : general testing requirements }\end{array}$ \\
\hline UNE 21143 & $\begin{array}{l}\text { Test of outer sheaths of cables that have a special protection } \\
\text { function and that are applied by extrusion }\end{array}$ \\
\hline $\begin{array}{l}\text { UNE-HD 632, UNE-EN 60811-4-1, } \\
\text { UNE-EN 60811-1-1 (EN 60811-1-1, IEC 811-1-1) }\end{array}$ & Component regulations for electrical cables \\
\hline
\end{tabular}




\section{Summary of Analyzed Applications}

Table 8 shows a summary of the applications and their degree of viability, based on the characteristics analyzed and the applicable regulations. In blue, the GTR polymeric combinations selected for each application reflect the suitable applications and the compounds with the maximum GTR amount allowed, according to the mechanical and electrical criterions.

Table 8. Summary of the analyzed applications that are viable with the analyzed material blends according to the applicable standards.

\begin{tabular}{|c|c|c|c|c|}
\hline $\begin{array}{l}\text { Components } \\
\text { Analyzed }\end{array}$ & $\begin{array}{l}\text { Electrical } \\
\text { Criterion }\end{array}$ & $\begin{array}{l}\text { Mechanical } \\
\text { Criterion }\end{array}$ & $\begin{array}{l}\text { Application } \\
\text { Standard }\end{array}$ & $\begin{array}{c}\text { Polymers + GTR } \\
\text { Suitable }\end{array}$ \\
\hline $\begin{array}{l}\text { Insulation for } \\
\text { electric shepherds }\end{array}$ & $\begin{array}{l}\text { Conductivity: } \\
<10^{-12} \mathrm{~S} / \mathrm{cm} \\
\operatorname{Tg} \delta<10^{4}\end{array}$ & $\begin{array}{l}\text { Tensile strength: } \\
12.5 \mathrm{MPa} \\
\text { Elongation at } \\
\text { break: } 300 \%\end{array}$ & $\begin{array}{l}\text { ITC-BT-39, 22, 23, } \\
24 \text { UNE-EN } \\
60335-2-76 \text { IEC } \\
60335-2-76\end{array}$ & $\mathrm{EVA}+10 \%$ \\
\hline $\begin{array}{l}\text { Spacer for power } \\
\text { lines }\end{array}$ & $\begin{array}{c}\text { Resistivity: }>5.5 \times \\
10^{5} \Omega \cdot \mathrm{cm}\end{array}$ & $\begin{array}{c}\text { Minimum tensile } \\
\text { strength: } 17.2 \mathrm{MPa} \\
\text { Minimum } \\
\text { elongation at break: } \\
300 \%\end{array}$ & IEC 61854 & $\mathrm{EVA}+20 \%$ \\
\hline $\begin{array}{c}\text { Universal electrical } \\
\text { cable joint }\end{array}$ & $\begin{array}{c}\text { Resistivity: }>10^{12} \\
\Omega \cdot \mathrm{cm}\end{array}$ & $\begin{array}{l}\text { Tensile strength: } \\
12.5 \mathrm{MPa} \\
\text { Elongation at } \\
\text { break: } 400 \%\end{array}$ & $\begin{array}{c}\text { IEC } 60840 \text { UNE HD } \\
628\end{array}$ & $\mathrm{EVA}+10 \%$ \\
\hline $\begin{array}{l}\text { Filler for electrical } \\
\text { applications }\end{array}$ & $\begin{array}{c}\text { Resistivity: }>10^{12} \\
\Omega \cdot \mathrm{cm}\end{array}$ & $\begin{array}{c}\text { Tensile strength: } \\
12.5 \mathrm{MPa} \\
\text { Elongation at } \\
\text { break: } 350 \%\end{array}$ & $\begin{array}{l}\text { UNE } 53 \text { 602; UNE } \\
53 \text { 510; UNE-HD } \\
\text { 632; UNE-EN } \\
\text { 60811-4-1 }\end{array}$ & $\mathrm{EVA}+10 \%$ \\
\hline $\begin{array}{l}\text { Trays and pipes for } \\
\text { electrical cables }\end{array}$ & $\begin{array}{c}\text { Resistivity: }>10^{12} \\
\Omega \cdot \mathrm{cm}\end{array}$ & $\begin{array}{c}\text { Elongation at } \\
\text { break: } 80 \pm 10 \% \\
\text { Tensile strength: } 15 \\
\mathrm{MPa}\end{array}$ & $\begin{array}{l}\text { UNE EN } 61537 \\
\text { UNE EN } 50085-1: \\
\text { IEC } 61537 \text { (EN } \\
\text { 61537). }\end{array}$ & $\begin{array}{c}\mathrm{PP}+10 \% \\
\mathrm{EVA}+10 \%\end{array}$ \\
\hline $\begin{array}{l}\text { Footwear for work } \\
\text { use (insulating) } \\
\text { Insulating: } \\
\text { High electrical } \\
\text { resistance: }\end{array}$ & $\begin{array}{c}\text { Resistivity: }>10^{6} \\
\Omega \cdot \mathrm{cm} \\
>10^{9} \Omega \cdot \mathrm{cm}\end{array}$ & $\begin{array}{c}\text { Tensile strength }> \\
\text { 10-12 MPa } \\
\text { Elongation at break } \\
>450 \%\end{array}$ & $\begin{array}{l}\text { UNE-EN ISO } \\
\text { 20345/6/7:2005 } \\
\text { UNE 53510 }\end{array}$ & $\mathrm{EVA}+10 \%$ \\
\hline
\end{tabular}

In Table 9, the critical criteria that the analyzed materials do not exceed are in red, as the standards criteria are for different applications, and any GTR polymer blends analyzed cannot cover the minimum values analyzed. Therefore, the red criteria determine applications not suitable for analyzed blends.

Table 9. Summary of the analyzed applications that are not viable with the analyzed material blends according to the applicable standards.

\begin{tabular}{cccc}
\hline Components Analyzed & Electrical Criterion & Mechanical Criterion & Application Standard \\
\hline $\begin{array}{c}\text { 1. Insulation for overhead } \\
\text { power lines }\end{array}$ & $\begin{array}{c}\text { Resistivity: } \\
>10^{14} \Omega \cdot \mathrm{cm}\end{array}$ & Tensile strength $>$ 25 MPa & UNE-21115 IEC 502 \\
\hline 2. Electrical insulating tape & $2 \times 10^{15} \Omega \cdot \mathrm{cm}$ & $\begin{array}{c}\text { Elongation at break: } 600 \% \\
\text { Tensile strength 1.5 MPa }\end{array}$ & IEC 60454-3 \\
\hline $\begin{array}{c}\text { 3. Protection in hands and } \\
\text { arms. Dielectric gloves }\end{array}$ & $10^{15} \Omega \cdot \mathrm{cm}$ & $\begin{array}{c}\text { Tensile strength } \geq 16 \mathrm{MPa} \\
\text { Elongation at break } \geq 600 \%\end{array}$ & UNE-EN 60903:2005 \\
\hline
\end{tabular}


The results of the application analysis are set out below along with the polymer compound initially selected for each specific application. The GTR polymeric compound combinations selected for each application are shown in the last column. Of the nine possible applications analyzed, three do not meet the imposed technical requirements (Table 9) and the rest, that is, six applications, become, initially viable (Tables 8 and 10).

Table 10. Selected compound for each application.

\begin{tabular}{cc}
\hline Selected Applications & Selected Compounds: Polymers + GTR \\
\hline 1. Electrical shepherds' insulation & $\mathrm{EVA}+10 \%$ \\
\hline 2. Spacer for electric lines & $\mathrm{EVA}+10 \%$ EVA $+20 \%$ \\
\hline 3. Joint for electrical cables universal & $\mathrm{EVA}+10 \%$ \\
\hline 4. Filling for electrical applications & $\mathrm{EVA}+10 \%$ \\
\hline 5. Tray and Pipes for electrical cables & $\mathrm{PP}+10 \%$ \\
\hline $\begin{array}{c}\text { 6. Work use footwear (insulated). Insulating } \\
\text { and high electrical resistance }\end{array}$ & $\mathrm{EVA}+10 \%$ \\
\hline
\end{tabular}

As a summary of the performed applications analysis, from the nine applications analyzed, we concluded that three are non-viable applications and six applications are feasible. The research balance is clearly positive, with six applications where GTR polymeric blends can be used for low-requirement insulation industrial applications, and the GTR recycling possibilities with these applications are increasing, due to the performed analysis.

\section{Conclusions on the Applications}

We found that the analyzed blends behaved, in general, as good electrical insulators; therefore they were accepted as good electrical insulators for low contents of GTR (5-10\%). The mechanical properties analysis proved that there was a wide variety of GTR polymeric blends with a low decrease in their mechanical properties (tensile strength and elongation at break). However, elongation at break was revealed as an important criterion in electrical applications and has high requirements due to the service demands that these components must give. All analyzed GTR polymer blends (PA, PS, ABS, $\mathrm{PP}, \mathrm{PVC}, \mathrm{EVA}$, and HDPE) obtained materials that were sufficiently insulating to constitute electrical insulators for different applications (conductivity $<10^{12} \mathrm{~S} / \mathrm{cm}$; resistivity $>10^{12} \Omega \cdot \mathrm{cm}$; tangent $\delta<10^{5}$ ). The tangent of $\delta$ values in all the samples analyzed with $10 \%$ GTR produced results well below $10^{5}$, as established by the analyzed UNE and IEC standards.

The electrical insulating characteristics of the materials decreased with the addition of GTR and therefore produced insulating blends with poor characteristics. However, for low GTR loads (5-10\%), the obtained samples has sufficient values for electrical insulation (conductivity, resistivity, tangent of $\delta$ ) and structural mechanical properties (tensile strength and elongation at break) for use in different insulator applications according to the UNE and IEC standards.

EVA-GTR is an interesting compound due to its electrical stability, conductivity, resistance, and loss tangent properties, as is shown in Figures 2 and 3, as well as in the elongation at break. We concluded that polymeric blends with GTR could be applied in different industrial components, such as electrical shepherds' insulation, spacers for electric lines, joints for universal electrical cables, fillings for electrical applications, trays and pipes for electrical cables, and plastic components for insulating footwear. These are different applications that can be applied to integrate and use waste GTR, and these represent an effort for environmental solutions for the huge amounts of waste that tire rubber presents in landfills all over the world, which are increased yearly. 
Author Contributions: Conceptualization: M.M.-G. and J.B.A.; Data curation: J.G.-A.; Formal analysis: X.C.F.; Investigation: M.M.-G.; Project administration: X.C.F.; Resources: L.M.V.; Software: J.G.-A.; Supervision: M.M.-G.; Validation: L.M.V.; Visualization: J.G.-A. and R.M.-R.; Writing—original draft: M.M.-G.; Writing一review and editing: R.M.-R., J.B.A. and X.C.F. All authors have read and agreed to the published version of the manuscript.

Funding: This research received no external funding.

Conflicts of Interest: The authors declare no conflict of interest.

\section{References}

1. Medina, N.F.; Garcia, R.; Hajirasouliha, I.; Pilakoutas, K.; Guadagnini, M.; Raoul, S. Composites with recycled rubber aggregates: Properties and opportunities in construction. Constr. Build. Mater. 2018, 188, 884-897. [CrossRef]

2. Karger-Kocsis, J.; Mészáros, L.; Bárány, T. Ground tyre rubber (GTR) in thermoplastics, thermosets, and rubbers. J. Mater. Sci. 2013, 48, 1-38. [CrossRef]

3. Ikeda, Y.; Kato, A.; Kohjiya, S.; Nakajima, Y. Rubber Science; Springer: Berlin/Heidelberg, Germany, 2018.

4. Rajan, V.V.; Dierkes, W.K.; Joseph, R.; Noordermeer, J.W.M. Science and technology of rubber reclamation with special attention to NR-based waste latex products. Prog. Polym. Sci. 2006, 31, 811-834. [CrossRef]

5. Akiba, M.; Hashim, A.S. Vulcanization and crosslinking in elastomers. Prog. Polym. Sci. 1997, $22,475-521$. [CrossRef]

6. Sienkiewicz, M.; Kucinska-Lipka, J.; Janik, H.; Balas, A. Progress in used tyres management in the European Union: A review. Waste Manag. 2012, 32, 1742-1751. [CrossRef]

7. Fazli, A.; Rodrigue, D. Waste rubber recycling: A Review on the evolution and properties of thermoplastic elastomers. Materials 2020, 13, 782. [CrossRef]

8. Colom, X.; Cañavate, J.; Carrillo, F.; Lis, M.J. Acoustic and mechanical properties of recycled polyvinyl chloride/ground tyre rubber composites. J. Compos. Mater. 2014, 48, 1061-1069. [CrossRef]

9. Cañavate, J.; Colom, X.; Saeb, M.R.; Przybysz, M.; Zedler, L.; Formela, K. Influence of microwave treatment conditions of GTR on physico-mechanical and structural properties of NBR/NR/GTR composites. AFINIDAD 2019, 76, 171-179.

10. Amari, T.; Themelis, N.J.; Wernick, I.K. Resource recovery from used rubber tires. Resour. Policy 1999, 25, 179-188. [CrossRef]

11. Ilkılıç, C.; Aydın, H. Fuel production from waste vehicle tires by catalytic pyrolysis and its application in a diesel engine. Fuel Process. Technol. 2011, 92, 1129-1135. [CrossRef]

12. Shah, J.; Jan, M.R.; Mabood, F. Catalytic conversion of waste tyres into valuable hydrocarbons. J. Polym. Environ. 2007, 15, 207-211. [CrossRef]

13. Van Beukering, P.J.; Janssen, M.A. Trade and recycling of used tyres in Western and Eastern Europe. Resour. Conserv. Recycl. 2001, 33, 235-265. [CrossRef]

14. Canavate, J.; Carrillo, F.; Casas, P.; Colom, X.; Sunol, J.J. The Use of Waxes and Wetting Additives to Improve Compatibility between HDPE and Ground Tyre Rubber. J. Compos. Mater. 2010, 44, 1233-1245. [CrossRef]

15. Rodgers, B.; Waddell, W. Tire engineering. In Science and technology of rubber; Mark, J.E., Erman, B., Eirich, F.R., Eds.; Elsevier Academic Press: Cambridge, MA, USA, 2011; pp. 619-661.

16. Behnood, A.; Olek, J. Rheological properties of asphalt binders modified with styrene-butadiene-styrene (SBS), ground tire rubber (GTR), or polyphosphoric acid (PPA). Constr. Build. Mater. 2017, 151, 464-478. [CrossRef]

17. Behnood, A.; Olek, J. Stress-dependent behavior and rutting resistance of modified asphalt binders: An MSCR approach. Constr. Build. Mater. 2017, 157, 635-646. [CrossRef]

18. Fukumori, K.; Matsushita, M.; Okamoto, H.; Sato, N.; Suzuki, Y.; Takeuchi, K. Recycling technology of tire rubber. JSAE Rev. 2002, 23, 259-264. [CrossRef]

19. Sunthonpagasit, N.; Duffey, M.R. Scrap tires to crumb rubber: Feasibility analysis for processing facilities. Resour. Conserv. Recycl. 2004, 40, 281-299. [CrossRef]

20. Ramarad, S.; Khalid, M.; Ratnam, C.; Chuah, A.L.; Rashmi, W. Waste tire rubber in polymer blends: A review on the evolution, properties and future. Prog. Mater. Sci. 2015, 72, 100-140. [CrossRef] 
21. Cañavate, J.; Casas, P.; Colom, X.; Nogués, F. Formulations for thermoplastic vulcanizates based on high density polyethylene, ethylene-propylene-diene monomer, and ground tire rubber. J. Compos. Mater. 2011, 45, 1189-1200. [CrossRef]

22. Liu, H.S.; Richard, C.P.; Mead, J.L.; Stacer, R.G. Development of Novel Applications for Using Recycled Rubber in Thermoplastics; Technical Research Program; Chelsea Center for Recycling and Economic Development, University of Massachusetts: Lowell, UK, 2000.

23. Orrit-Prat, J.; Mujal-Rosas, R.; Rahhali, A.; Marin-Genesca, M.; Colom-Fajula, X.; Belana-Punseti, J. Dielectric and mechanical characterization of PVC composites with ground tire rubber. J. Compos. Mater. 2016, 45, 1233-1243. [CrossRef]

24. Colom, X.; Carrillo, F.; Canavate, J. Composites reinforced with reused tyres: Surface oxidant treatment to improve the interfacial compatibility. Compos. Part A-Appl. Sci. Manuf. 2007, 38, 44-50. [CrossRef]

25. Mujal, R.; Orrit-Prat, J.; Ramis-Juan, X.; Marin-Genesca, M. Electrical application of polyamide reinforced with old tire rubber (ground tire rubber): Dielectric, thermal, mechanical and structural properties. J. Thermoplast. Compos. Mater. 2014, 27, 1209-1231. [CrossRef]

26. Mujal, R.; Orrit-Prat, J.; Ramis-Juan, X.; Marin-Genesca, M.; Rahhali, A. Study on dielectric, thermal, and mechanical properties of the ethylene vinyl acetate reinforced with ground tire rubber. J. Reinf. Plastics Compos. 2011, 30, 581-592. [CrossRef]

27. Marín-Genescà, M.; García-Amorós, J.; Mujal-Rosas, R.; Salueña Berna, X.; Massagués Vidal, L. Comparison of Mechanical and Electrical Characteristics of Various Polymers Blended with Ground Tire Rubber (GTR) and Applications. Appl. Sci. 2019, 9, 1564. [CrossRef]

28. Evangelista, L.; de Brito, J. Mechanical behavior of concrete made with fine recycled concrete aggregates. Cement and concrete composites. Cem. Concr. Compos. 2007, 29, 397-401. [CrossRef]

29. El-Nashar, D.E.; Eid, M.A.M.; Abou Aiad, T.H.; Abd-El-Messieh, S.L. Electrical and Mechanical Investigations on Polyvinyl Chloride Filled with HAF Black. J. Reinf. Plast. Compos. 2009, 28, 1763-1773. [CrossRef]

30. Mujal, R.; Orrit, J.; Ramis, X.; Marín-Genescà, M.; Rahhali, A. Study on dielectric, mechanical and thermal properties of polypropylene (PP) composites with ground tyre rubber (GTR). Polym. Polym. Compos. 2012, 20, 755-766.

31. Yehia, A.; Mull, M.A.; Ismail, M.N.; Hefny, Y.A.; Abdel-Bary, E.M. Effect of chemically modified waste rubber powder as a filler in natural rubber vulcanizates. J. Appl. Polym. Sci. 2004, 93, 30-36. [CrossRef]

32. Mujal, R.; Marin, M.; Orrit, J.; Rahhali, A.; Colom, X. Dielectric, mechanical, and thermal characterization of high-density polyethylene composites with ground tire rubber. J. Thermoplast. Compos. Mater. 2012, 25, 537-559. [CrossRef]

33. Tang, H.; Chen, X.; Luo, Y. Studies on the PTC/NTC effect of carbon black filled low density polyethylene composites. Eur. Polym. J. 1997, 33, 1383-1386. [CrossRef]

34. Feller, J.F.; Linossier, I.; Levesque, G. Conductive polymer composites (CPCs): Comparison of electrical properties of poly(ethylene-co-ethyl acrylate)-carbon black with poly(butylene terephthalate)/poly(ethyleneco-ethyl acrylate)-carbon black. Polym. Adv. Technol. 2002, 13, 714-724. [CrossRef]

35. Zhang, J.F.; Zheng, Q.; Yang, Y.Q.; Yi, X.S. High-density polyethylene/carbon black conductive composites. I. Effect of CB surface modification on its resistivity-temperature behavior. J. Appl. Polym. Sci. 2002, 83, 3112-3116. [CrossRef]

36. Ehsani, M.; Borsi, H.; Gockenbach, E.; Bakhsahnde, G.R.; Morshedian, J.; Abedi, N. Study of electrical, dynamic mechanical and surface properties of silicone-EPDM blends. In Proceedings of the 2004 IEEE International Conference on Solid Dielectrics, 2004, ICSD 2004, Toulouse, France, 5-9 July 2004; Volume 1, pp. 431-434.

37. Marín-Genescà, M.; García-Amorós, J.; Mujal-Rosas, R.; Massagués, L.; Colom, X. Study and Characterization of the Dielectric Behavior of Low Linear Density Polyethylene Composites Mixed with Ground Tire Rubber Particles. Polymers 2020, 12, 1075. [CrossRef]

38. Ishimoto, K.; Tanaka, T.; Ohki, Y.; Sekiguchi, Y.; Murata, Y.; Gosyowaki, M. Comparison of Dielectric Properties of Low-density Polyethylene/MgO Composites with Different Size Fillers. In Proceedings of the Annual Report Conference on Electrical Insulation and Dielectric Phenomena, 2008, CEIDP 2008, Quebec, QC, Canada, 26-29 October 2008; pp. 208-211.

39. Günter, G. Seip_Electrical Installations; Wiley-VCH Verlag GmbH: Weinheim, Germany, 2000. 
40. Shinyama, K.; Fujita, S. Mechanical and Electrical Properties of Biodegradable Plastics. In Proceedings of the International Symposium on Electrical Insulating Materials, Kitakyushu, Japan, 5-9 June 2005.

41. Standards UNE and IEC; AENOR: Madrid, Spain, 1993.

42. New Spanish Low Voltage Electrotechnical Regulation; Marcombo: Barcelona, Spain, 2020.

(C) 2020 by the authors. Licensee MDPI, Basel, Switzerland. This article is an open access article distributed under the terms and conditions of the Creative Commons Attribution (CC BY) license (http://creativecommons.org/licenses/by/4.0/). 